\title{
Specialization, Information, and Growth: A Sequential Equilibrium Analysis
}

\author{
Yew-Kwang Ng and Xiaokai Yang \\ CID Working Paper No. 7 \\ March 1999
}

(C) Copyright 1999 Yew-Kwang Ng, Xiaokai Yang, and the President and Fellows of Harvard College

\section{Working Papers Center for International Development at Harvard University}




\title{
Specialization, Information, and Growth: A Sequential Equilibrium Analysis
}

\author{
Yew-Kwang Ng and Xiaokai Yang*
}

\begin{abstract}
Pricing costs and information problems are introduced into a framework with consumer-producers, economies of specialization, and transaction costs to predict the endogenous and concurrent evolution in division of labor and in the information of organization acquired by society. The concurrent evolution generates endogenous growth based on the tradeoff between gains from information about the efficient pattern of division of labor, which can be acquired via experiments with various patterns of division of labor, and experimentation costs, which relate to the costs in discovering prices. The concept of Walras sequential equilibrium is developed to analyze the social learning process which is featured with uncertainties of the direction of the evolution as well as a certain trend of the evolution.
\end{abstract}

Keywords: Coevolution of specialization and information, adaptive decision, bounded rationality, sequential equilibrium, economic development.

JEL codes: D23, D50, D90, O12.

Yew-Kwang Ng is Chair Professor at the Department of Economics, Monash University, and Fellow of Australian Adacemy of Social Sciences. His research interests include welfare economics, biology and economics, and division of labor.

Xiaokai Yang is a Research Fellow at the Center for International Development. His research interests include equilibrium network of division of labor, endogenous comparative advantages, inframarginal analysis of patterns of trade and economic development.

\footnotetext{
*The authors are grateful to the referee for Review of Development Economics, Jeff Borland, Bob Rice, and participants of an AEA session on development economics and of International Symposium on Dynamic Modeling for helpful comments. Financial support from Australia Research Council is gratefully acknowledged. We are responsible for any remaining errors.
} 


\title{
Specialization, Information, and Growth: A Sequential Equilibrium Analysis
}

\author{
Yew-Kwang Ng and Xiaokai Yang
}

\section{Introduction}

The purpose of the paper is two fold. First, it shall explore the implications of interactions between evolution in division of labor and evolution in information about the efficient pattern of division of labor that is acquired by society through the price system for economic growth. Second, we shall develop the notion of Walrasian sequential equilibrium to model concurrent evolution in division of labor and in information of organization acquired by society.

Recent development of endogenous growth model, represented by Judd [1985], Romer [1990], Grossman and Helpman [1989], and Yang and Borland [1991] not only explains economic growth by endogenous accumulation, but also explains growth by evolution in division of labor which generates increases in the number of goods and in individuals' levels of specialization as two aspects of economic development. The spontaneous evolution in division of labor in the models not only generates growth phenomena (growth in per capita real income, in productivity, and in per capita consumption) in the absence of exogenous changes in parameters, but also generates development phenomena, such as increases in individuals' levels of specialization, in the number of traded goods, in the degree of market integration, in the degree of diversification of economic structure, in the number of markets, in income share of transaction costs, and so on. In contrast, neoclassical growth models, represented by Ramsey [1928], can only generate evolution in per capita real income or in per capita consumption, although they may generate endogenous growth in the absence of exogenous changes in parameters, as shown by Barro and Sala-i-Martin [1995].

However, evolution in division of labor in the literature of endogenous growth is generated by a deterministic mechanism based on individuals' dynamic decisions with infinite horizon. This evolutionary process involves no uncertainties. As Nelson [1995] points out, real economic growth process is an 
evolutionary process that is featured with uncertainties of the direction of the evolution and with a certain trend of the evolution. The first purpose of the present paper is to develop an endogenous growth model that generates an evolutionary process of division of labor, characterized by the two features.

Since productivity depends on the level and pattern of division of labor that is chosen by individuals while information about the efficient level and pattern of division of labor acquired by society determines which level and pattern of division of labor will be chosen, the dynamic nature of the information acquisition is essential for us to understand economic development. As shown by Yang and Ng [1993], an individual's decision on his level and pattern of specialization is always a corner solution. As he changes his level of specialization, he discontinuously jumps from a corner solution to another corner solution. Hence, a person can only use total benefit-cost analysis to identify the optimum corner solution after he has conducted marginal analysis of each corner solution. The discontinuity of decision variables across corner solutions generates two kinds of complexities. Suppose it takes a period of time for a person to try a corner solution, then for a given set of prices, a person can sort out the optimum corner solution only after a sufficiently large number of periods. However, market prices that are available are determined by each and every individuals' decisions to choose a certain corner solutions. For instance, no market prices will be available if all individuals choose an autarkic corner solution that involves no trade (that is, quantities of traded goods are 0). Hence, individuals' decisions to choose corner solutions determine what information on prices is available, while the information determines individuals' decisions in choosing their levels and patterns of specialization (or in choosing corner solutions). When time dimension is spelt out, the interactions between information and dynamic decisions will generate concurrent evolution in information about the efficient pattern of organization acquired by society and evolution in the level of division of labor that is chosen by individuals.

An example may illustrate the nature of the information acquisition process. Founding of McDonald restaurant network can be considered as an experiment with a pattern of high level of division of labor between specialized production of management and planning and specialized production of direct 
services within the franchise and between specialized production of food and specialized production of other goods. Since all variables and demand and supply functions are discontinuous from corner solution to corner solution, marginal analysis based on interior solutions cannot provide the founder of this franchise with the information for right decision. The founder of McDonald restaurant network decided to use the market to experiment with his new pattern of business organization that involves a higher level of division of labor within the franchise and between the franchise and the rest of the economy. Instead of adjusting prices at the margin, he tried a price of restaurant services that was much lower than the prevailing price of restaurant services. According to his calculation, the higher level of division of labor would generate productivity gains, on the one hand, and more transaction costs, on the other. His franchise arrangements may reduce transaction costs to the extent that the benefit of the higher level of division of labor outweigh its cost, so that the substantially lower price of services can stand with the test of the social experiment. This idea was substantiated later, as we have seen in real world. However, the founder may go to bankruptcy if the business was proved by the social experiment to be inefficient compared to the prevailing pattern of organization prior to the experiment. But the social experiment through the price system is necessary for society to acquire the information about the efficient pattern of division of labor, even if it generates business failure because of the interdependency between decisions in choosing a pattern of organization and available information of prices and because of discontinuity of decision variables between different patterns of division of labor.

Kreps and Wilson's concept of sequential equilibrium might be a vehicle for analyzing the interactions between dynamic strategies and information. However, it is a formidable job to endogenize evolution in division of labor in addition to endogenization of the interactions between dynamic decision and information using their concept. Usually, even without the endogenization of evolution of division of labor, only extremely simple models of sequential equilibrium can be solved. Hence, the second purpose of the paper is to develop the concept of Walrasian sequential equilibrium that makes modeling of endogenous evolution in division of labor and evolution in information of organization tractable. The concurrent 
evolution in division of labor and in information acquired by society through the price system are based on adaptive behavior and on limited horizon, so that it is closer to a real economic development process than what is predicted by Romer [1990] and Yang and Borland's endogenous growth models [1991] with spontaneous evolution in division of labor based on perfect information and infinite decision horizon. Somehow, the present paper bridges the literature of endogenous growth and the literature of bounded rationality (see Conlisk [1996] for a recent survey on the latter literature).

In the model to be considered, there are many ex ante identical consumer-producers with preferences for diverse consumption and production functions displaying economies of specialization. Complicated interactions between economies of specialization and transaction costs in the market generate uncertainties about real income for different patterns of division of labor. Each person's optimal decision is a corner solution. Combinations of different corner solutions generate many possible candidates (corner equilibria) for general equilibrium. Individuals may experiment with each possible pattern of division of labor via a Walrasian auction mechanism at a point in time and thereby eliminate uncertainties and acquire information about the efficient pattern of division of labor over time. However, the costs in discovering prices generate a tradeoff between information gains and experimentation costs in the information acquisition process. A decentralized market will trade off gains from information acquisition against experimentation costs to determine the equilibrium pattern of experiments with patterns of division of labor over time. In the process, individuals use Bayes' rule and dynamic programming to adjust their beliefs and behavior according to updated information. Hence, we refer to the solution to the model as Walras sequential equilibrium. The determinants of the dynamics of the Walras sequential equilibrium are transportation cost coefficient for trading one unit of goods, degree of economies of specialization, discount rate, and pricing cost coefficient.

Suppose the transportation cost coefficient and the degree of economies of specialization are fixed. If pricing costs are high, then the market will not experiment with any sophisticated pattern of division of labor. If pricing costs are sufficiently low, all possible patterns of division of labor will be experimented 
with. In this process, simple patterns of division of labor are experimented with before the more complicated ones are, so that a gradual evolution of division of labor may occur. If pricing costs are at an intermediate level, then only simple patterns of division of labor will be experimented with, so that society cannot acquire all information about the efficient economic organization. For a fixed pricing cost coefficient, more patterns of division of labor will be experimented with as the transportation cost coefficient decreases and/or as the degree of economies of specialization increases.

Our concept of Walras sequential equilibrium is an analogue to Kreps and Wilson's concept of sequential equilibrium. In the game model of Kreps and Wilson [1982], players use dynamic programming to choose strategies for a given sequence of their beliefs of their opponents' types and the sequence of beliefs is updated according to the Bayes rule and the observed strategies. In our model, individuals use dynamic programming to solve for their experimentation sequence with different patterns of division of labor for given information of the ranking of each person's incomes generated by various patterns of specialization. The information is updated according to the Bayes rule and observed prices. The difference between our concept of Walras sequential equilibrium and Kreps and Wilson's concept of sequential equilibrium will be discussed in section 3 .

Compared to Again et al [1991], the result in this paper is more limited to a specific model because the discontinuity of payoff functions in a general equilibrium model based on corner solutions makes intractable a model that is as general as Aghion's. Because of corner solutions and discontinuity of payoff functions across corner solutions, we assume the absence of information in this paper, while incomplete information is assumed in Aghion et al. An experimentation cost in addition to the discount rate is specified as generated by the process of discovering prices. By contrast, the experimentation cost in Aghion et al is generated only by the discount rate. Finally, our model is a general equilibrium model while Aghion's model is a partial equilibrium model. This makes our model more difficult to manage, so that we confine attention to a specific model where all individuals' decisions on learning by experimenting with the patterns of economic organization are symmetric. The symmetry avoids the problem of coordination and mismatch 
in experimentation with various patterns of the division of labor, thereby keeping the model tractable at the cost of realism. We leave the analysis of a more realistic model with the coordination problem caused by information asymmetry, which may generate interesting implications of the role of entrepreneurship in experiments with economic organization, to future research.

This paper is organized as follows. Section 1 specifies an equilibrium model that endogenizes the determination of the efficient pattern of the division of labor in a Walrasian regime. Section 2 introduces a pricing cost and the information problem into the model to generate a story about learning by experimenting with various patterns of the division of labor. Section 3 solves for the dynamic equilibrium and discusses the implications of the results.

\section{The Efficient Pattern of Division of Labor in a W alrasian Regime}

The model in this section is the same as in $Y$ ang [1990]. In the next section, the time dimension and a fixed pricing cost for possible transactions will be introduced. There are $\mathrm{M}$ ex ante identical consumerproducers where $M$ is assumed large. The respective quantities of the three consumer goods self-provided are denoted by $x, y$, and $z$. The respective quantities of the three goods sold are denoted by $x^{s}, y^{s}$, and $z^{s}$. The respective quantities of the three goods bought are denoted by $x^{d}, y^{d}$, and $z^{d}$. The transaction cost of a unit of goods purchased is $1-k$, so that $k x^{d}, k y^{d}$, or $k z^{d}$ is the amount available for consumption after purchasing a good. U tility for all consumer-producers is a Cobb-D ouglas function of quantities consumed:

$$
u=\left(x+k x^{d}\right)\left(y+k y^{d}\right)\left(z+k z^{d}\right),
$$

Each consumer-producer's system of production is:

$$
\begin{aligned}
& x+x^{s}=1 x^{\alpha}, \quad y+y^{s}=1 y^{\beta}, \\
& z+z^{s}=I_{z}^{\gamma} \quad \alpha>\beta>\gamma>1 \\
& \left.\right|_{x}+l_{y}+\left.\right|_{z}=1, \quad \mathrm{l}_{i} \in[0,1],
\end{aligned}
$$

where $l_{i}$ is a person's labor share in producing good $i$ which is defined as his level of specialization in producing good i. This system of production function and endowment constraint displays economies of 
specialization since labor productivity of good i increases with a person's level of specialization in producing good $\mathrm{i}$.

A Walrasian regime is assumed. Proposition 1 in $Y$ ang [1990], which states that a person sells at most one good and does not buy and produce the same goods, can also be established for the model in this paper. A combination of zero and non-zero variables that is compatible with this proposition is called a configuration. There are ten configurations which may be divided into three classes. The first class is autarky, denoted by $\mathrm{A}$ and shown in Fig la where circles represent configurations and lines with arrows represent flows of goods. The configurations from the second class are denoted by (i/j). A n individual choosing (i/j) sells and self-provides good $\mathrm{i}$ and buys good j. He does not buy good $\mathrm{i}$ and does not produce good $j$. He self-provides good $r \neq i, j$. That is, $i, i^{s}, j^{d}, r, l_{i}, l_{r}>0$ and $i^{d}=j^{s}=j=r^{s}=r^{d}=l_{j}$ =0. There are six configurations from this class: $(x / y),(y / x),(x / z),(z / x),(y / z),(z / y)$. Configurations $(\mathrm{x} / \mathrm{y})$ and $(\mathrm{y} / \mathrm{x})$ are shown in Fig $1 \mathrm{~b}$. The configurations from the third class are denoted by (i/jr) and shown in Fig 1c. An individual choosing (i/jr) self-provides and sells good $i$ and buys goods $j$ and $r$, that is, $i, i^{s}, j^{d}, r^{d}, l_{i}>0$ and $i^{d}=j=j^{s}=r=r^{s}=l_{j}=l_{r}=0$. There are three configurations from this class: $(x / y z),(y / x z),(z / x y)$ 


\section{Figure 1: $\quad$ Endogenous Evolution of the Division of Labor Based on Experiments with}

Patterns of the Division of L abor

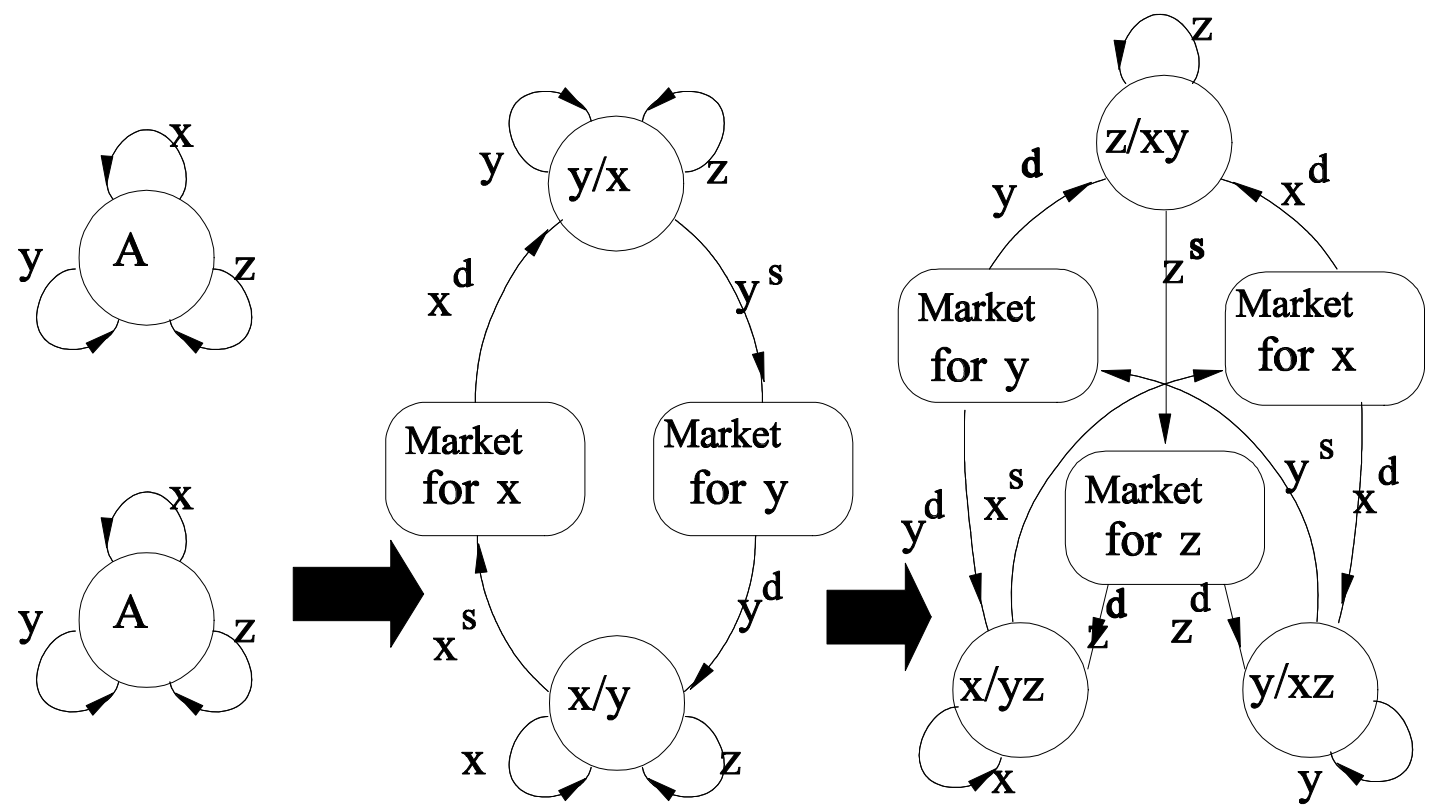

(a) Autarky

(b) Partial division of labor

(c) Complete division of labor

A combination of configurations that is compatible with the market clearing conditions is called a market structure or simply a structure. There are five structures derived from feasible combinations of the ten configurations. A utarky itself is a structure. Hence, a corner solution for A is a corner equilibrium. Three market structures are referred to as partial division of labor with goods $i$ and $j$ traded and denoted by $P(i j)$. $P(i j)$ consists of configurations $(i / j)$ and $(j / i) . P(x y)$ is shown in Fig $1 b$. Finally, market structure $\mathrm{C}$, the complete division of labor shown in Fig $1 \mathrm{C}$, consists of configurations (x/yz), $(y / x z)$, and $(z / x y)$. The market clearing and utility equalization conditions determine a corner equilibrium for each market structure with trade.

Following $\mathrm{Y}$ ang and $\mathrm{Ng}$ [1993, chapter 6], it can be shown that the $\mathrm{W}$ alrasian equilibrium is the corner equilibrium that generates the highest per capita real income. Following the two-step approach to solving for equilibrium based on corner solutions, developed in $Y$ ang [1990], the following lemma has been established in A ppendix A, which is available from the first author upon reqest. It is shown in $\mathrm{Y}$ ang [1990] that only market structure $P(x y)$ out of the three market structures with the partial division of labor 
is the equilibrium and $P(x z)$ and $P(y z)$ cannot be the equilibrium when two goods are traded if $\alpha>\beta>\gamma$. We will denote $P(x y)$ by $P$ when no confusion is caused. In lemma $1 k_{1}=\left[(2 \alpha+\gamma)^{2 \alpha+\gamma}(2 \beta+\gamma)^{2 \beta+\gamma}\right]^{5} / 2^{\alpha+\beta-}$ ${ }^{2}(\alpha+\beta+\gamma)^{\alpha+\beta+\gamma}, k_{2} \equiv 3^{3} 2^{\alpha+\beta-2} \alpha^{\alpha} \beta^{\beta} \gamma^{\gamma} /\left[(2 \alpha+\gamma)^{2 \alpha+\gamma}(2 \beta\right.$ $\left.\left.+\gamma)^{2 \beta+\gamma}\right]^{5}, k_{3} \equiv\left[3^{3} \alpha^{\alpha} \beta^{\beta} \gamma^{\gamma} /(\alpha+\beta+\gamma)^{\alpha+\beta+\gamma}\right]\right]^{.5}$.

\section{Lemma 1}

(1) Assume that $k_{2}>k_{1}$

The equilibrium is autarky (A) if transaction efficiency $k<k_{1}$. The equilibrium is the partial division of labor (P) where the relative price of the traded goods is $p_{y} / p_{x}=$ $(2 \alpha)^{\alpha}(2 \beta+\gamma)^{\beta+.5 \gamma} /(2 \beta)^{\beta}(2 \alpha+\gamma)^{\alpha+.5 \gamma}$ and the relative number of different specialists is $M_{y} / M_{x}=$ $(2 \alpha+\gamma) /(2 \alpha+\gamma)]^{.5 \gamma}$ if $\mathbf{k} \in\left(\mathbf{k}_{1}, \mathbf{k}_{2}\right)$. The equilibrium is the complete division of labor (C) where $p_{x}=p_{y}=p_{z}$ and $M_{x}=M_{y}=M_{z}$ if $k>k_{2}$.

(2) Assume that $k_{2}<k_{1}$

The equilibrium is autarky if transaction efficiency $k<k_{3}$. The equilibrium is the complete division of labor if $k>k_{3}$. The partial division of labor can never be an equilibrium. The partial division of labor generates a greater value of per capita real income than autarky iff $k>k_{1}$. 


\section{Costs in Acquiring Information about the E fficient Pattern of the Division of L abor}

In this section, a time dimension is introduced into the model. The decision horizon of an individual is assumed to be limited and discrete. There are three periods for an individual's decision problem. It is assumed that in period $0, M$ individuals are in autarky. They must decide which market structure, among autarky, partial division of labor, and complete division of labor, to experiment with in each of periods 1,2 , 3. For this dynamic model, it is possible that individuals experiment with one of several corner equilibria via a Walrasian auction mechanism over each period.

Individuals may find the corner equilibrium that maximizes their real income if they have experimented with all market structures through such a Walrasian pricing mechanism. In this section we will specify the dynamic model. Then, the next section solves for the dynamic equilibrium which determines the experimentation pattern as a function of the parameters of pricing efficiency, transportation efficiency, the degree of economies of specialization, and the discount factor.

Suppose that the utility function and the system of production for each consumer-producer are the same as in the preceding section, independent of time. It is further assumed that a fraction, $1-s$, of an individual's expected utility disappears because of pricing costs in the experiment with the transactions in one corner equilibrium in a period, but no pricing costs are incurred for the similar transactions in subsequent periods. In a Walrasian regime, a Walrasian pricing mechanism sorts out relative prices of

traded goods through communications between the Walrasian auctioneer and each individual in a tatonnement process. The pricing cost is incurred in the communication process. Note that an exchange of good $x$ for good $y$ in structure $\mathrm{P}$ is considered to be different from an exchange of good $x$ for good $y$ in structure $\mathrm{C}$ since the relative price of the goods may differ between the two market structures. Assume further that a person can choose at most one configuration involving trade in any period and thereby society can experiment at most with one market structure in each period. Also, as soon as individuals have found the relative prices in a corner equilibrium, they can instantly choose between this structure and those which 
had been previously experimented with. For instance, if individuals have experimented with structure $\mathrm{P}$ in period 1, then they can immediately choose whichever is better between structures A and P in the end of period 1. Suppose that the pricing cost coefficient, which is equivalent to an experimentation cost coefficient of a structure, is infinitesimally smaller for structure $\mathrm{P}$ than that for structure $\mathrm{C}$ because each person must find the relative prices of three traded goods in $\mathrm{C}$, but only the relative price of two traded goods in $\mathrm{P}$.

In period 0 , each individual has information on autarky, but has no information about other individuals' parameters of preference, production function, and endowments and about relative prices in market structure $\mathrm{P}$ or $\mathrm{C}$. Therefore, they cannot obtain complete information about economic organization unless they have experimented with the other two market structures. The assumption that all individuals have no information of the relative prices in market structures $\mathrm{P}$ and $\mathrm{C}$ implies that they have no information about their real incomes in the two market structures. This assumption of the absence of information differs from the assumption of incomplete information. For the assumption of incomplete information, a person knows the distribution function of his real income in market structure $\mathrm{P}$ or $\mathrm{C}$. For the assumption of the absence of information, a person does not know such a distribution function. What he knows is that the ranking of real income in structures $\mathrm{A}, \mathrm{P}$, and $\mathrm{C}$ is subject to a certain distribution.

An individual's information set in period 0 is specified as follows. He knows that three types of configurations may generate three levels of real income. Let the per capita real income in autarky be $u_{\mathrm{A}}$, that in the partial division of labor be $u_{\mathrm{P}}$, and that in the complete division of labor be $u_{\mathrm{C}}$. Each individual knows the real value of $u_{\mathrm{A}}$, but does not know the real values of $u_{\mathrm{P}}$ and $u_{\mathrm{C}}$. Nor does he know the distribution functions of $u_{\mathrm{P}}$ and $u_{\mathrm{C}}$. Signifying the ranking of real income by the order of letters, there are six possible rankings of per capita real income: $u_{\mathrm{A}} u_{\mathrm{P}} u_{\mathrm{C}}, u_{\mathrm{A}} u_{\mathrm{C}} u_{\mathrm{P}}, u_{\mathrm{P}} u_{\mathrm{A}} u_{\mathrm{C}}, u_{\mathrm{P}} u_{\mathrm{C}} u_{\mathrm{A}}, u_{\mathrm{C}} u_{\mathrm{A}} u_{\mathrm{P}}, u_{\mathrm{C}} u_{\mathrm{P}} u_{\mathrm{A}}$. For instance, $u_{\mathrm{P}} u_{\mathrm{A}} u_{\mathrm{C}}$ implies that structure $\mathrm{P}$ generates the highest per capita real income, structure $\mathrm{C}$ generates the lowest per capita real income, and structure A generates an intermediate level of per capita real income. Suppose that in period 0 each individual knows that the difference between the two consecutive levels of per 
capita real income generated by the three structures is $b$. Each individual's subjective distribution density is that each state occurs with probability $1 / 6$. Since real value of $b$ depends on the degree of economies of specialization, he estimates $\mathrm{b}$ according to the following rule. Let parameter of the degree be $\mathrm{a}$, then $a=(\alpha, \beta, \gamma)$. Assume a person's prior knowledge of the relationship between $b$ and $a$ is $b=f_{i}(a)$. $f_{i}($.$) depends on$ the ranking of real incomes generated by the three structure. Suppose $\mathrm{b}=\mathrm{f}_{1}(\mathrm{a})$ for ranking $u_{\mathrm{A}} u_{\mathrm{P}} u_{\mathrm{C}}$. For this ranking, a lower level of division of labor generates a higher level of per capita real income. But an increase in the degree of economies of specialization, a, will increase per capita real income in a structure with a higher level of division of labor thereby reducing the difference between consecutive levels of real incomes, b. Hence, $\mathrm{df}_{1} / \mathrm{da}<0$. Suppose $\mathrm{b}=\mathrm{f}_{2}(\mathrm{a})$ for ranking $u_{\mathrm{A}} u_{\mathrm{C}} u_{\mathrm{P}}, \mathrm{b}=\mathrm{f}_{3}(\mathrm{a})$ for ranking $u_{\mathrm{P}} u_{\mathrm{A}} u_{\mathrm{C}}, \mathrm{b}=\mathrm{f}_{4}(\mathrm{a})$ for ranking $u_{\mathrm{P}} u_{\mathrm{C}} u_{\mathrm{A}}, \mathrm{b}=\mathrm{f}_{5}(\mathrm{a})$ for ranking $u_{\mathrm{C}} u_{\mathrm{A}} u_{\mathrm{P}}$, and $\mathrm{b}=\mathrm{f}_{6}(\mathrm{a})$ for ranking $u_{\mathrm{C}} u_{\mathrm{P}} u_{\mathrm{A}}$. Following the same logic for proving $\mathrm{df}_{1} / \mathrm{da}<0$, it can be shown that $\mathrm{df}_{2} / \mathrm{da}<0$ between structures $\mathrm{A}$ and $\mathrm{C}$ and $\mathrm{df}_{2} / \mathrm{da}>0$ between structure $\mathrm{C}$ and $\mathrm{P} ; \mathrm{df}_{3} / \mathrm{da}>0$ between structures $\mathrm{P}$ and $\mathrm{A}$ and $\mathrm{df}_{3} / \mathrm{da}<0$ between structure $\mathrm{A}$ and $\mathrm{C} ; \mathrm{df}_{4} / \mathrm{da}<0$ between structures $\mathrm{P}$ and $\mathrm{C}$ and $\mathrm{df}_{4} / \mathrm{da}>0$ between structure $\mathrm{C}$ and $\mathrm{A} ; \mathrm{df}_{5} / \mathrm{da}>0$ between structures $\mathrm{C}$ and $\mathrm{A}$ and $\mathrm{df}_{5} / \mathrm{da}<0$ between structure $\mathrm{A}$ and $\mathrm{P} ; \mathrm{df}_{6} / \mathrm{da}>0$. Since each of the 6 rankings takes place with equal probability, the estimate of $\mathrm{b}$ at $\mathrm{t}=0$ is

$$
(1 / 6) \sum_{i} f_{i}(a)
$$

We define this "information set" to be characterized by the absence of information because the expected value of $u_{\mathrm{P}}$ (or $u_{\mathrm{C}}$ ) equals $u_{\mathrm{A}}$, which implies that a person does not know more than real value of $u_{\mathrm{A}}$, and the entropy of the system with the six states is at its maximum, which implies that the information that a person has is at its minimum. The expected value of $u_{\mathrm{P}}\left(\right.$ or $\left.u_{\mathrm{C}}\right)$ is $(1 / 3)\left[\left(u_{\mathrm{A}}+b\right)+\left(u_{\mathrm{A}}-b\right)\right]+(1 / 6)\left[\left(u_{\mathrm{A}}+2 b\right)+\left(u_{\mathrm{A}}-2 b\right)\right]=$ $u_{\mathrm{A}}$. The entropy of the system with six states is $-6(1 / 6) \log _{2}(1 / 6)=2.5850$ bits that is the maximum level of entropy for a system with six states. ${ }^{1}$

Entropy is maximized when each and every state occurs with equal probability. M aximum entropy implies minimum information. 
As soon as any one of structures $\mathrm{P}$ and $\mathrm{C}$ is experimented with, a person's knowledge of $\mathrm{b}$ is updated according to the Bayes law and the observed difference $\left|\mathrm{u}_{\mathrm{A}}-\mathrm{u}_{\mathrm{P}}\right|$ or $\left|\mathrm{u}_{\mathrm{A}}-\mathrm{u}_{\mathrm{C}}\right|$ which is dependent on the parameters of production, transactions, and tastes. For instance, if a person decides to try structure $\mathrm{P}$ in period 1 and he finds $\mathrm{u}_{\mathrm{A}}>\mathrm{u}_{\mathrm{P}}$ after he has seen prices in structure $\mathrm{P}$ and has calculated his utility according to the prices. Then at the end of period $1, u_{\mathrm{P}} u_{\mathrm{A}} u_{\mathrm{C}}, u_{\mathrm{P}} u_{\mathrm{C}} u_{\mathrm{A}}$, and $u_{\mathrm{C}} u_{\mathrm{P}} u_{\mathrm{A}}$ are ruled out according to the Bayes rule since the three rankings are incompatible with $\mathrm{u}_{\mathrm{A}}>\mathrm{u}_{\mathrm{P}}$. Suppose the observed difference between $\mathrm{u}_{\mathrm{A}}$ and $\mathrm{u}_{\mathrm{P}}$ is b' and each individual still believes that true $b$ is the same between consecutive real income levels. Then b' equals b with conditional probability $2 / 3$ since $u_{\mathrm{A}} u_{\mathrm{P}} u_{\mathrm{C}}$ takes place with probability $1 / 3$ and $u_{\mathrm{C}} u_{\mathrm{A}} u_{\mathrm{P}}$ takes place with probability $1 / 3$ after a person has seen $b^{\prime}=u_{A}-u_{P}>0$, while $u_{A}-u_{P}=b$ for the 2 rankings. Also, $b^{\prime}$ equals $2 b$ with conditional probability $1 / 3$ since $u_{A} u_{C} u_{P}$ takes place with probability $1 / 3$ after a person has seen $b^{\prime}=u_{A}-u_{P}>0$, while $u_{A}-u_{C}=u_{C}-u_{P}=b=(1 / 2)\left(u_{A}-u_{P}\right)=(1 / 2) b^{\prime}$ for this ranking. Therefore, the expected value of $b$ is $(2 / 3) b^{\prime}+(1 / 3) 2 b^{\prime}=5 b^{\prime} / 6$ after a person has seen $b^{\prime}=u_{A^{-}}-u_{P}>0$.

With the knowledge about $\mathrm{b}$ and rankings of per capita real incomes in different structures, each individual can calculate his expected real income in order to make a decision on the optimal pattern of experiments with market structures. He has chosen an experimentation pattern even if he stays with autarky forever. This special pattern of experimentation with organization can be denoted AAAA, that is, the initial state is structure $\mathrm{A}$ and $\mathrm{A}$ is chosen in periods 1,2 , and 3. If an individual chooses configuration ( $\mathrm{i} / \mathrm{j})$ in period 1 and (i/jr) in period 2 and stays with the one that generates the highest real income among the three configurations, then structure $\mathrm{P}$ will be experimented with in period 1 and structure $\mathrm{C}$ will be experimented with in period 2. Here there is no difficulty for individuals to match each other's choices of configurations for two reasons. First, each person's objective function, specified in (4) below, is affected only by the difference in the number of traded goods. The difference between $(\mathrm{i} / \mathrm{j})$ and $(\mathrm{j} / \mathrm{i})$ or between $(\mathrm{i} / \mathrm{jr})$ and $(\mathrm{j} / \mathrm{ir})$, or (r/ij) has no effect on each person's real income because of the utility equalization condition. Due to the same discount rate, the same information, and the same pricing cost coefficient for all individuals, players will choose the same number of traded goods and they have no difficulty in coordinating the choice of the 
same number of traded goods. This implies that if a person chooses configuration $(\mathrm{i} / \mathrm{j})$ in period 1 , then nobody will choose $(\mathrm{i} / \mathrm{jr})$ in the same period.

Second, players will not have difficulties in matching each other's choice of different occupations (configurations) as soon as they participate in the Walrasian auction mechanism in a certain period after they have chosen the pattern of experimentation sequence. Appendix A, available upon request, shows that the indirect utility function of a specialist producer of good $i$ increases with the price of good $i$ in terms of other goods. The market clearing condition implies that the price of good $\mathrm{i}$ in terms of good $\mathrm{j}$ is inversely related to the number of specialist producers of good i relative to those of good j. Hence, when the number of specialists of a good is small, the price of this good will be high, so that the utility level of the specialists will be high. Thus, individuals have incentives to choose this profession. This implies that a person has an incentive to choose configuration $(\mathrm{i} / \mathrm{j})$ if other individuals choose $(\mathrm{j} / \mathrm{i})$.

In the absence of mismatch, market structure $\mathrm{P}$ will be chosen if an individual chooses configuration (i/j) and market structure $\mathrm{C}$ will be chosen if an individual chooses configuration (i/jr). If structure $\mathrm{P}$ is experimented with in period 1 , then the Walrasian relative prices in structure $\mathrm{P}$ will be ascertained via a Walrasian auction mechanism. As soon as the corner equilibrium relative price in structure $\mathrm{P}$ is ascertained in period 1, each individual can calculate his real income in structure $\mathrm{P}$. He will choose autarky if $u_{\mathrm{A}}>u_{\mathrm{P}}$. Otherwise he will choose structure $\mathrm{P}$. Denoting an expectation formed in period $t$ by $\mathrm{E}_{t}$, the utility level in period $\tau$ expected in period $t$ for option $i(\tau)$ can be expressed as $\mathrm{E}_{t}\left[u_{\tau}(i)\right]$, where $i=\mathrm{A}, \mathrm{P}$, C. In period 0 a person expects that he will receive utility $\mathrm{E}_{0}\left[u_{1}(\mathrm{P})\right]$ in period 1 if he chooses $\mathrm{P}$ in period 1. If the pricing cost, the discount factor, and what a person knows in period 0 are taken into account, in period 0 he expects his real income for period 1 to be

$$
E_{0}\left[u_{1}(P)\right]=\operatorname{sr}\left[(1 / 2) u_{A}+(1 / 3)\left(u_{A}+b\right)+(1 / 6)\left(u_{A}+2 b\right)\right]=\operatorname{sr}\left(u_{A}+2 b / 3\right)
$$

2 It can be assumed that in a period individuals have to choose the structure tried in that period even if they have found out it inferior to the structure previously chosen and that they can return back to the better previous structure only in the next period. This assumption will substantially complicate the algebra, but contribute little to the explaining power of the model. 
where he decides to choose configuration (i/j) in period 1 . Here $s$ is the fraction of expected real income that has been received. The fraction 1-s is assumed to disappear because of pricing cost. 1-s is a person's fixed communication cost with the Walrasian auctioneer. The cost is necessary for sorting out the relative prices in the structure concerned and is independent of quantities to trade. The discount factor $r$ is between 0 and 1 . The probability for $u_{A}$ to be $M$ ax $\left\{u_{A}, u_{P}\right\}$ is .5 because $u_{A} u_{p} u_{c}$ occurs with probability $1 / 6$ and so does $u_{A} u_{C} u_{p}$ or uc $u_{A} u_{P}$. Hence, if a person chooses the structure that generates the highest real income to him after the experiment with structure $P$, he receives $U_{A}$ with probability .5. He receives $u_{A}+b$ with probability $1 / 3$ because up $u_{A} u_{c}$ occurs with probability $1 / 6$ and so does uc up $u_{A}$ and because the difference between two consecutive levels of real income is $b$. He receives $u_{A}+2 b$ with probability $1 / 6$ because upucuA occurs with probability $1 / 6$ and the maximum difference between two levels of real income is $2 b$. Note that a person knows $u_{A}$ but does not know the values of up and uc in period 0 . He uses (3a) to estimate $b$ at $t=0$.

From (3b) a tradeoff exists between potential gains arising from information generated by experiments and pricing costs incurred in such experiments. Without the experiment with structure $\mathrm{P}$ in period 1, a person receives ruA in period 1. He expects to receive a higher discounted real income $r\left(u_{A}\right.$ $+2 b / 3)$ if he experiments with structure $P$ at the cost $(1-s) r\left(u_{A}+2 b / 3\right)$. However, such experimentation costs are incurred only once. If he does not experiment with structure $C$ in periods 2 and 3 , he can receive expected discounted real income $r^{2}\left(u_{A}+2 b / 3\right)$ in period 2 and $r^{3}\left(u_{A}+2 b / 3\right)$ in period 3 without experimentation costs. If he experiments with structure $C$ in period 2 , he expects to receive $\operatorname{sr}^{2}\left(u_{A}+b\right)$ in period 2 and $r^{3}\left(u_{A}+b\right)$ in period 3. The pricing cost coefficient 1-s can be interpreted as an investment in acquisition of information regarding organization. It generates perpetual benefits at the cost of current consumption. Current real income decreases because of the experimentation costs but the discounted future real income increases because of the perpetual benefits generated by the experiments. Hence, this tradeoff between preferences for current real income over future income, represented by the discount 
factor, and gains to information regarding organization is similar to the conventional tradeoff between the preference for current consumption and the productivity gains to investment.

If a structure with trade is experimented with in period 1, then individuals will sort out the relative prices of traded goods and relative numbers of individuals choosing different configurations through a Walrasian auction mechanism. U sing the updated information, each individual can calculate his real income in the structure and decide if he implements the transactions. Since the values of the relative prices and relative numbers of different specialists in the corner equilibria are the same for all individuals,

the updated information is the same for all individuals. Using the Bayes rule, each individual updates his beliefs of ranking of utilities in different structures and adjusts his dynamic decision of further experimentation with the structures that have not been experimented with. The utility equalization condition in each corner equilibrium implies that all individuals' adjustment of dynamic decisions based on the updated beliefs are consistent with one another. Hence, no coordination problem exists.

\section{Information Costs and E ndogenous Evolution of the Division of $L$ abor}

The concept of Walras sequential equilibrium is defined and an individual's dynamic programming problem in period 0 is specified and solved in subsection 3.1. In subsection 3.2 an individual's dynamic programming problems in other periods are solved using the Bayes rule. The Walras sequential equilibrium is then solved.

\subsection{Pattern of Experiment with Organization in Period 0}

Sequential equilibrium is defined as a fixed point which satisfies the following conditions. (1) In each period each individual maximizes his total discounted utility with respect to the sequence of configurations 
and quantities of goods produced, consumed, and traded for given history of the system and his information in this period; (2) Each individual's information is updated on the basis of observed prices, using Bayes' rule; and (3) A sequence of relative number of individuals who choose different configurations and a sequence of relative prices of all traded goods clear the markets for goods and equalize utilities across individuals in each period. The difference between the concept of Walras sequential equilibrium and K reps and W ilson's concept of sequential equilibrium is that (i) our sequential equilibrium consists of several Walrasian static equilibria over periods and (ii) in each period, each individual has a dynamic programming problem over subsequent periods which might be different from his dynamic programming problem in the next period because of adaptive decisions to updated information. The difference (i) implies that in K reps and W ilson's sequential equilibrium, there are direct interactions between individuals' strategies and information while in our sequential equilibrium interactions between information and individuals' decisions take place indirectly through a sequence of Walrasian equilibria which are fixed points determined by the interactions between prices and quantities over several periods. If information asymmetry is introduced into our model, a coordination problem will generate a story which is more like the story based on Kreps and Wilson's concept of sequential equilibrium.

An individual's dynamic decision problem in period 0 can be represented by a dynamic programming problem that is illustrated in Figure 2. Nodes in Figure 2 denote the options available to an individual. An option can be either a structure that an individual can choose to experiment with or a pattern of experiment. In period 1 , an individual can choose one out of $A$ (staying with autarky), $P$ (experimenting with structure $\mathrm{P}$ and choosing the best among all structures that have been experimented with), and $\mathrm{C}$ (experimenting with structure $\mathrm{C}$ and choosing the best between all structures that have been experimented with). The payoff generated by an option is denoted by the letters above the line that leads 
to the option in the next period. For instance, option $A$ in period 1 generates utility $u_{\equiv} u_{A}$, option $P$ in period 2 generates discounted utility $\operatorname{srv} \equiv s r\left(u_{A}+2 b / 3\right)$.

This system remembers whatever happened before. Thus, the options available in period 2 are more numerous than in period 1 . Options $A, P$, and $C$ in period 2 are the same as in period $1 . \quad$ Node PO denotes the option that a person experiments with structure $P$ in period 1 and no new experiment in period 2 when he stays with the best between $A$ and $P$. Node CO denotes the option that a person experiments with structure $C$ in period 1 and no new experiment in period 2 when he stays with the best between $A$ and $C$. A sequence of option $P$ in period 1 and $C$ in period 2 implies that a person is informed about relative prices in all corner equilibria. Following the procedure for calculating $E_{0}\left[u_{1}(P)\right]$, given by equation (3b), the expected discounted real income for option $C$ in period 2 following $P$ in period 1 is sr ${ }^{2}$ $\left(u_{A}+b\right)$. The two further options PO and $C O$ in period 2 that are distinctive from any options available in period 1, underline the fact that payoffs depend not only upon current options, but also upon the time path of decisions in the past. Such an option generates discounted expected real income in period $2, r^{2}\left(u_{A}\right.$ $+2 b / 3)$, which differs from that generated by option $C$ in period $2, \mathrm{sr}^{2}\left(u_{A}+b\right)$. A person will not experiment with a structure that has been experimented with previously due to the perpetual value of information on organization. Hence, a person will experiment with structure $C$ in a given period only if he has not previously experimented with that structure.

Options A, P, C, PO, and CO in period 3 are the same as in period 2. However, there is one more option PCO available in period 3 because payoffs depend on the decision path. Option PCO denotes that a person has experimented with structures $\mathrm{P}$ and $\mathrm{C}$ and stays in period 3 with the best among $A, P$, and $C$. Therefore, there are six terminal points in period 3. Payoffs associated with a certain option are indicated above the line leading to the corresponding node in Figure 2.

The objective function for the dynamic programming problem at $\mathrm{t}=0$ is

(4a) M ax: $\quad \Sigma_{t=1}{ }^{3} E_{0}\left[r^{t} u_{t}(i)\right]$ 
$i(t)$

where $i(1)=A, P, C, i(2)=A, P, C, P O, C O, i(3)=A, P, C, P O, C O, P C O$, and

(4b) $\quad E_{0}\left[r u_{1}(A)\right]=r u_{A}, E_{0}\left[r u_{1}(P)\right]=E_{0}\left[r u_{1}(C)\right]=\operatorname{sr}\left(u_{A}+2 b / 3\right)$;

$E_{0}\left[r^{2} u_{2}(A)\right]=r^{2} u_{A}$,

$E_{0}\left[r^{2} U_{2}(P)\right]=E_{0}\left[r^{2} u_{2}(C)\right]=s r^{2}\left(u_{A}+2 b / 3\right)$ if $A$ is experimented with in period 1 ;

$E_{0}\left[r^{2} U_{2}(P)\right]=E_{0}\left[r^{2} U_{2}(C)\right]=s r^{2}\left(U_{A}+b\right)$ if $C$ or $P$ is experimented with in period 1;

$E_{0}\left[r^{2} u_{2}(P O)\right]=E_{0}\left[r^{2} u_{2}(C O)\right]=r^{2}\left(u_{A}+2 b / 3\right) ;$

$E_{0}\left[r^{3} u_{3}(A)\right]=r^{3} u_{A} ;$

$E_{0}\left[r^{3} u_{3}(P)\right]=E_{0}\left[r^{3} u_{3}(C)\right]=s r^{3}\left(u_{A}+2 b / 3\right)$ if only $A$ is previously experimented with;

$E_{0}\left[r^{3} u_{3}(P)\right]=E_{0}\left[r^{3} u_{3}(C)\right]=s r^{3}\left(u_{A}+b\right)$ if $C$ or $P$ is previously experimented with;

$E_{0}\left[r^{3} u_{3}(P O)\right]=E_{0}\left[r^{3} u_{3}(C O)\right]=r^{3}\left(u_{A}+2 b / 3\right) ;$

$E_{0}\left[r^{3} u_{3}(P C O)\right]=E_{0}\left[r^{3} u_{3}(C P O)\right]=r^{3}\left(u_{A}+b\right)$.

Figure 2: Dynamic Programming Problem

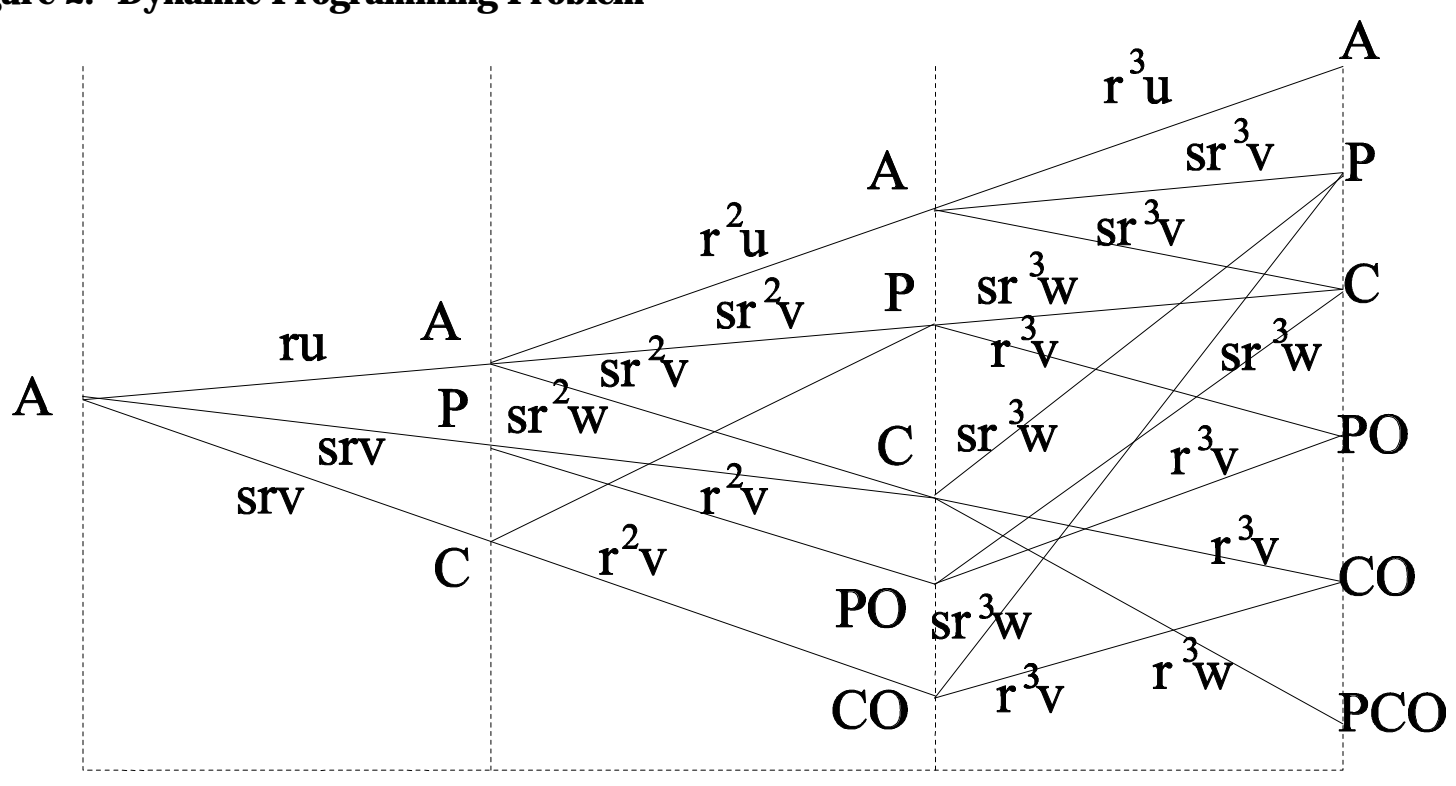

Period 0

Period 1

Period 2

Period 3 
where $u \equiv u_{A}, v \equiv u_{A}+2 b / 3, w \equiv u_{A}+b$.

Figure 2 provides an intuitive illustration of the payoffs for different options in the three periods.

A pplying the Bellman optimality principle, a backward decision rule yields the solution to the dynamic programming problem in period 0 . This solution is summarized in Table 1 . The technical detail of the derivation of the solution is in A ppendix B, which is available upon request. Due to the same information, same discount rate, and same pricing cost coefficient, which is slightly larger for structure $\mathrm{C}$ than for structure $\mathrm{P}$, for all individuals, individuals' dynamic decisions on optimal patterns of experiments with organization are symmetric. Hence, all individuals will experiment with the same market structure in each period.

\section{Table 1: Solution of the Dynamic Programming Problem in Period 0}

\begin{tabular}{||c|c|c||}
\hline \hline$s<s_{0}$ & $s \in\left(S_{0}, S_{1}\right)$ & $s>s_{1}$ \\
\hline AAAA & APOO & APCO \\
\hline
\end{tabular}

where $s_{0} \equiv\left[u_{A}+2 b r(1+r) / 3\right] /\left(u_{A}+2 b / 3\right), s_{1} \equiv\left[u_{A}+b(2-r) / 3\right] /\left(u_{A}+b\right)$, and $s_{1}>s_{0}$.

In Table 1 pattern AAAA denotes autarky from period 0 to period 3. Pattern APOO denotes autarky in period 0 , an experiment with the partial division of labor in period 1 , and the best between $\mathrm{A}$ and $\mathrm{P}$ being chosen in periods $1,2,3$. Pattern A PCO denotes autarky in period 0 , an experiment with $\mathrm{P}$ in period 1 , an experiment with $C$ in period 2 , the best between $A$ and $P$ being chosen in period 1 , and the best among $A, P$, and $C$ being chosen in periods 2 and 3. Table 1 shows that individuals will stay with autarky forever and to undertake no experiments with structure $\mathrm{P}$ or $\mathrm{C}$ if pricing efficiency $\mathrm{s}<\mathrm{s}$. One structure involving trade will be experimented with and the best between $A$ and that structure will be chosen in period 1 if $s \in\left(s_{0}, s_{1}\right)$. Two structures involving trade will be experimented with over periods 1 and 2 and the best among $A$ and them will be chosen if $s>s_{1}$ 


\subsection{Walras sequential equilibrium}

Now, suppose $s>s_{0}$, then structure $P$ will be experimented with in period 1 . Hence, uncertainties about value of $u_{P}$ and about the ranking of $u_{A}$ and $u_{p}$ are solved after the relative price $p_{x} / p_{y}$ and relative number $\mathrm{M}_{\mathrm{x}} / \mathrm{M}_{\mathrm{y}}$ are sorted out by the Walrasian auction mechanism. With the updated information, each individual knows up $>u_{A}$ iff $k>k_{1}$. A ssume $k>k_{1}$, then each person's updated information based on

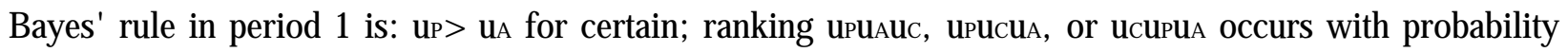
1/3. Also, updated estimate of $b$ can be calculated according to observed $u_{p}-u_{A}$ and the Bayes rule. On the basis of the updated information, each person can specify a dynamic programming problem from period 1 to period 3 , which is analogous to the one in (4). For $k<k_{1}$ or other values of $k$, similar but different problems can be specified. Following an analogous backward decision rule, the dynamic programming problems can be solved. The solution to each individual's all dynamic programming problems in periods 0,1 , and 2, together with the corner equilibrium relative prices of traded goods and relative numbers of different specialists in relevant structures, determine the $W$ alras sequential equilibrium. Which sequence of structure is associated with the sequential equilibrium depends upon the values of the parameters of transportation efficiency, pricing efficiency, degree of economies of specialization, and discount factor. The sequential equilibrium and its comparative dynamics are summarized in Fig. 3. The corresponding sequential equilibrium relative prices and relative numbers of different specialists can be found from lemma 1. 


\section{Figure 3: The Sequential E quilibrium}

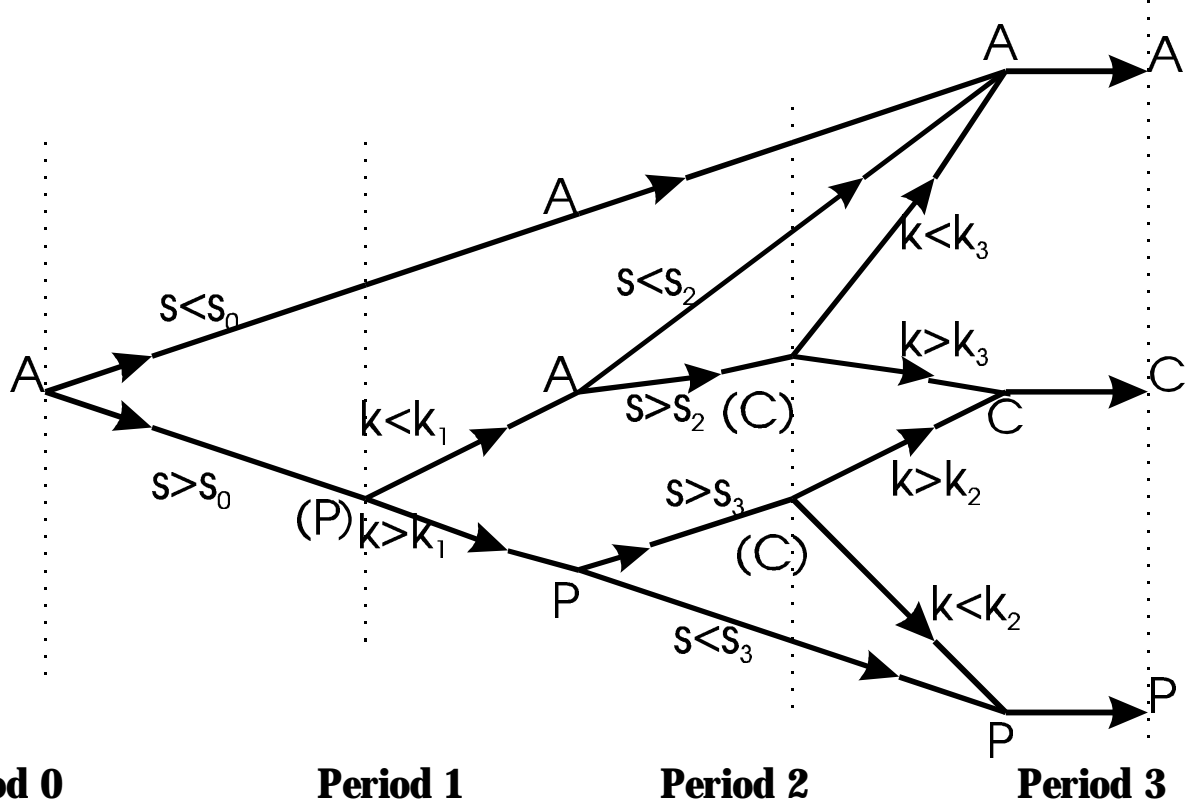

where the capitalized letters in brackets represent the structures that have been experimented with in a certain period and those without brackets represent the structures that have been chosen. $s_{0} \equiv\left[u_{A}+2 b r(1+r) / 3\right] /\left(u_{A}+2 b / 3\right), s_{2} \equiv\left(u_{A}-b r / 3\right) /\left(u_{A}+b / 3\right)>s_{0}, s_{3} \equiv\left(u_{P}-b r / 3\right) /\left(u_{P}+b / 3\right), k_{1} \equiv[(2 \alpha$ $\left.+\gamma)^{2 \alpha+\gamma}(2 \beta+\gamma)^{2 \beta+\gamma}\right]^{5} / 2^{\alpha+\beta-2}(\alpha+\beta+\gamma)^{\alpha+\beta+\gamma}, \mathrm{k}_{2} \equiv 3^{3} 2^{\alpha+\beta 2} \alpha^{\alpha} \beta^{\beta} \gamma^{\gamma} /\left[(2 \alpha \gamma)^{2 \alpha+\gamma}(2 \beta+\gamma)^{2 \beta+\gamma}\right]^{5}, \mathrm{k}_{3} \equiv\left[3^{3} \alpha^{\alpha} \beta^{\beta} \gamma^{\gamma} /(\alpha\right.$ $\left.+\beta+\gamma)^{\alpha+\beta+\gamma}\right]^{5}$. Also,

$$
\mathrm{S}_{3}>\mathrm{S}_{2} \text { iff } \mathrm{k}>\mathrm{k}_{1} \text {. }
$$

From Fig. 3 we can see that if $k$ is fixed such that $k<k_{3}$, then no structure with trade will be experimented with and no information will be acquired by society for $s<s_{0}$. Structure $P$ will be experimented with in period 1 but autarky will be finally chosen over all periods if $s \in\left(\mathrm{s}_{0}, \mathrm{~s}_{2}\right)$. Hence, partial information will be acquired by society. Structure $\mathrm{P}$ will be experimented with in period 1 and structure $\mathrm{C}$ will be experimented with in period 2 but autarky will be finally chosen over all periods if s> S2. All information of relative price, relative numbers of different specialists, and real incomes for structures $P$ and $C$ which are given in lemma 1 are learned by individuals over the three periods despite 
the fact that $P$ and $C$ are not finally chosen. This implies that more structures will be experimented with as pricing efficiency s increases for a fixed transportation efficiency $k$.

Fig. 3 indicates also that if $s$ is fixed such that $s \in\left(s_{3}, s_{2}\right)$ for $k<k_{1}$ or $s>s_{3}$ for $k>k_{1}$, then only structure $P$ is experimented with in period 1 and autarky is finally chosen over all periods if $k_{1}<k_{1}$; structure $\mathrm{P}$ will be experimented with in period 1 and $\mathrm{C}$ will be experimented with in period 2 and $\mathrm{P}$ will be finally chosen over period 1 and $C$ will be chosen over periods 2 and 3 if $k>k_{1 .}{ }^{3}$ This implies that for a fixed value of pricing efficiency that is not too small, more structures will be experimented with and a higher level of division of labor will be finally chosen as transportation efficiency increases (for fixed values of $\alpha, \beta$, and $\gamma$ ). Since $k_{i}$ decrease with $\alpha, \beta$, and $\gamma$, this implies that more structures will be experimented with and a higher level of division of labor will be finally chosen as the degree of economies of specialization, $\alpha, \beta$, or $\gamma$ increases if transportation efficiency $k$ is fixed. Since $s_{2}$ and $s_{3}$ decrease with $r$, more structures will be experimented with as the discount factor increases (or as the discount rate decreases) if other parameters are fixed.

For $s>s_{3}$ and $k>k_{1}$, sequential equilibrium involves gradual evolution of division of labor from autarky in period 0 first to partial division of labor in period 1, finally ending up with complete division of labor in periods 2 and 3. All individuals have gradually learnt and implemented all prices and real incomes generated by various patterns of division of labor. The concurrent evolution of division of labor and information will generate progress in productivity as well as many other structural changes. The concurrent evolution of productivity and the division of labor may occur due to the information gains from learning by experimentation with different patterns of the division of labor even in the absence of learning by producing goods that was specified in $Y$ ang and Borland [1991]. It is interesting to note the following feature of the concurrent evolution. Individuals did not know where the system head for at $t=0$.

Here, we have used the facts based on (5) that $s_{2}<s_{3}$ and thereby $s \in\left(s_{3}, s_{2}\right)$ is impossible if $k>k_{1}$ and that $s_{2}>s_{3}$ and thereby $s_{(}\left(s_{3}, s_{2}\right)$ is possible if $k<k_{1}$. 
They gradually learn the direction of the evolution as they use adaptive decision rule to resolve uncertainties. Despite of the uncertainties of the direction of the evolution, it displays a trend from simple to complex patterns of division of labor. The adaptive behavior, uncertainties of the direction of evolution, and a certain trend of the evolution distinguish our endogenous growth from deterministic endogenous growth models of J udd, Romer, Grossman-H elpman, and Y ang-Borland.

The algebra for establishing the results in Fig. 3 is in A ppendix B, available upon request. The results yield the following proposition.

\section{Proposition 1}

Autarky is chosen over all periods and no experiments with organizational patterns will take place and therefore no information about economic organization can be acquired by society if pricing efficiency $s$ is too low and/or the discount rate is too large. All market structures will be experimented with and society will acquire complete information about economic organization via the price system if pricing efficiency, transportation efficiency, the degree of economies of specialization and the discount factor are sufficiently large. More market structures will be experimented with, more information of organization will be acquired, and a higher level of division of labor will be finally chosen as pricing efficiency, transportation efficiency, the degree of economies of specialization, and/or discount factor increase. If pricing efficiency, transportation efficiency, and the degree of economies of specialization are sufficiently large, a gradual evolution of the division of labor and productivity will take place.

In terms of terminology in Aghion et al [1991], this proposition identifies the conditions under which adequate learning will or will not occur. However, the difference is that the condition for adequate 
social learning to occur in our model is a sufficiently high pricing efficiency and a sufficiently low discount rate, while it is in Aghion et al that the payoff function is analytical or is smooth and quasiconcave or the discount rate is zero.

Figure 1 gives an intuitive illustration of the evolution of the division of labor. In period 0 , individuals are in autarky, as shown in panel (a), where there are no markets or trade, and productivity is low because economies of specialization cannot be exploited. For sufficiently great pricing efficiency, transportation efficiency, and degree of economies of specialization, the partial division of labor illustrated in panel (b) will be experimented with and chosen in period 1. There are two markets, and hence each person must undertake two transactions to obtain all necessary goods. Each individual sells one good, self-provides two goods, and trades two goods. The degree of production concentration is higher than in autarky. Each individual's level of specialization is higher than in autarky. The number of distinct professional sectors (configurations) is two. This implies that the economic structure where each individual has a higher level of specialization is more diverse than in autarky, that is, specialization and diversification are two sides of the division of labor.

Finally, the complete division of labor will be experimented with and will be chosen in period 2 . Trade dependence, productivity, the number of traded goods, the number of markets, the diversity of the economic structure, production concentration, and the level of specialization for each person are all higher than in the partial division of labor. In particular, the size of the market network and the degree of integration of the market increase as the division of labor evolves over time.

For the model presented in this paper a gradual evolution of the division of labor will not occur in the absence of experimentation costs of economic organization if $\mathrm{k}_{2}<\mathrm{k}_{1}$. Individuals will either jump to the complete division of labor and stay there forever (if $k>k_{2}$ ) or remain in autarky forever (if $k<k_{2}$ ). The experimentation costs of economic organization restrain individuals from obtaining all information about economic organization within a single period, and therefore it takes time for people to experiment 
with all possible patterns of the division of labor and to obtain complete information regarding economic organization. In this process, a gradual evolution of the division of labor will be observed even if the complete division of labor given perfect information is most efficient.

The essence of the model presented in this paper is that knowledge of economic organization determines productivity and technical conditions. Suppose $k>k_{2}$, then the production possibility frontier and the welfare frontier are associated with the complete division of labor. However, due to pricing costs and the lack of information about organization an economy may remain in autarky forever if pricing efficiency (i.e. experimentation efficiency) and/or the discount factor are sufficiently small. This point becomes even more evident if many goods are introduced into the model such that the number of patterns of the division of labor and the number of experimentation patterns are increased. In this case the number of periods that is necessary for experimenting with all possible patterns of the division of labor will increase more than proportionally. For a completely symmetric model, the number of possible distinctive patterns of the division of labor is $m-1$ if there are $m$ goods. The number becomes $\Sigma_{n=0}^{m} C^{n} m=2^{m}$ if $n$ out of $\mathrm{m}$ goods are traded and preference and production parameters differ across goods, where $C^{n} m$ is $n$ combination of $m$ factors. Suppose there are 100 goods $(m=100)$ and it takes one day for an economy to experiment with one pattern of the division of labor. It will take $2^{100} / 365 \approx 3.34 \times 10^{27}$ years to have experimented with all patterns of the division of labor. This indicates the significant implications of the information costs of organization for economic growth.

This theory can be used to tell the following story. Several thousand years ago, if people had had a very developed division of labor and a right pattern of the division of labor, they could have developed modern technology by employing gains arising from the sophisticated division of labor within a relatively short period of time. However, they failed to achieve this not just because of a technical constraint, but also because of the lack of information about the efficient pattern of the division of labor that may generate advanced technology. If this story makes sense, then we can see how substantial is the 
information cost of organization. This cost constrained people to a low level of productivity for several thousand years. That is, it took such a long time for people to experiment with sufficiently many patterns of the division of labor that they were not able to find the efficient one until the Industrial Revolution in Britain during the eighteenth century.

\section{Concluding Remarks}

This paper has shown that the price system is a way to coordinate experiments with economic organization. The price system does not convey all information about efficient organization if all possible patterns of organization have not been experimented with. As long as pricing costs are not trivial and people are short of information about the efficient pattern of the division of labor, the most efficient pattern of organization may not be experimented with and therefore may not be found out in a dynamic equilibrium based on rational behavior in the absence of information. A certain irrational behavior based on limited information may increase the chance for experiments with all possible patterns of organization including efficient as well as inefficient ones. The seemingly irrational experiments with inefficient patterns of organization are necessary for identifying the efficient pattern from the inefficient ones.

A $n$ increase in pricing efficiency $s$ or transportation efficiency $k$ may increase a chance for more patterns of organization to be experimented with. Institutional arrangements, urbanization, the legal system, government policies, and technical conditions for transactions, all affect pricing efficiency in experiments with patterns of economic organization and thereby determines productivity and welfare. The angle from which we approach the informational role of prices differs from one through which Grossman [1989] approaches this issue. He has shown that the price system works in a way that it seems to convey all information to everybody. We have shown that the price system may not carry all information about economic organization if experiments with organization have not exhausted all possible 
patterns of organization. The price system is only a vehicle for individuals to coordinate experiments with organization that are necessary for acquiring information about the efficient pattern of the division of labor.

The other implication of our model for development economics is that it can be used to explain a big jump (rather than a big push) in the industrialization process in a less developed country. ${ }^{4} \mathrm{~A}$ less developed country as a newcomer in the industrialization process can always obtain free information on the efficient pattern of the division of labor. He can mimic the organizational pattern that has been proven to be efficient via the experiments with organizational patterns in developed countries. Hence, a gradual evolution of the division of labor is no longer efficient for newcomers. A big jump industrialization to a very high level of division of labor from autarky is possible. In terms of our model in section 2 if k> k2, a newcomer can jump, over structure $P$, to structure $C$ from autarky, if other countries have already experimented with $\mathrm{P}$ and $\mathrm{C} .^{5}$

Our story here is consistent with Y oung's idea [1928] that savings and investments are not a matter of available resources and technology, but rather they are a matter of the evolution of the division of labor. In our model, the experimentation cost is a sort of investment in acquiring the information about the efficient pattern of division of labor that determines productivity and technical progress.

$4 \quad$ Murphy, Shleifer, and Vishny (1989a, b) have developed some formal models to explain big push industrialization by some factors other than low information costs for a newcomer.

5 It is unrealistic to attribute all obstacles for economic growth to experimentation cost of organization because we can find many less developed countries which cannot exploit information provided by organizational experiments in developed economies. If learning by doing specified in $Y$ ang and Borland [1991] is introduced into the current model with learning by experimenting with organization, then a blend of the two kinds of learning may yield a more realistic story. 


\section{R eferences}

A ghion, P., Bolton, P., and Jullien, B. (1991): "Optimal Learning by Experimentation", Review of Economic Studies, 58: 621-54.

Barro, T. and Sala-i-M artin, X. (1995): Economic Growth, New Y ork, M cGraw-Hill.

Conlisk, John (1996), “Why Bounded Rationality?” The J ournal of E conomic Literature, 34, 669-700.

Grossman, G. and Helpman, E. (1989), "Product Development and International Trade", J ournal of Political Economy, 97, 1261-83.

Grossman, S. (1989): The Informational Role of Prices, M IT Press.

Kreps, D. and Wilson, R. (1982): "Sequential Equilibria", Econometrica, 50: 863-94.

Murphy, K., Shleifer, A., and Vishny, R. (1989a): "Industrialization and the Big Push", Journal of Political Economy, 97: 1003-26.

----- (1989b): "Income Distribution, Market Size, and Industrialization", The Quarterly J ournal of Economics 104, A ugust, 537-564.

Nelson, R. (1995), "Recent Evolutionary Theorizing A bout Economic Change", Journal of Economics Litureture, 33, 48-90.

Ramsey (1928), "A M athematical Theory of Saving", Economic J ournal, 38, 543-59.

Romer, P. (1990), "Endogenous Technological Change", J ournal of Political Economy, 98, S71-S102.

Smith, A dam (1776): An Inquiry into the Nature and Causes of the Wealth of Nations. Reprint, edited by E. Cannan. Chicago: University of Chicago Press, 1976.

Y ang, X. (1990): "Development, Structural Changes, and Urbanization". J ournal of Development Economics, 34: 199-222.

Y ang, X. and Borland, J. (1991): "A M icroeconomic M echanism for Economic Growth". Journal of Political Economy, 99: 460-82.

Y ang, $\mathrm{X}$. and Ng, Y-K. (1993): Specialization and Economic Organization, a New Classical Microeconomic Framework, A msterdam, North-Holland.

Y ang, X. and N g, S. (1997): "Specialization and Division of Labor: A Survey," in K. A rrow, Y-K. Ng, and $\mathrm{X}$. Y ang eds. "Increasing Returns and Economic Analysis," London, M cmillian.

Y oung, A. (1928): "Increasing Returns and Economic Progress", The Economic J ournal, 152: 527-542. 


\section{Appendix A: Proof of Lemma 1}

This appendix first solves for the corner solutions and corner equilibria in market structures $A, P$, and $C$ in static Walrasian model specified in section 2.

(1) The decision problem for configuration or structure A is

$$
M a x: u=x y z=\left|x^{\alpha}\right| y^{\beta}\left(1-\mid x_{x}-I_{y}\right)^{\gamma}
$$

$\mid x, I_{y}$

The maximum value of $u$ for autarky is

$$
u_{A}=\alpha^{\alpha} \beta^{\beta} \gamma^{\gamma} /(a+\beta+\gamma)^{\alpha+\beta+\gamma}
$$

(2) M arket structure $P(x y)$ consisting of configurations $(x / y)$ and $(y / x)$.

(2.a) The decision problem for configuration $(x / y)$ is

$$
\begin{aligned}
& M \text { ax: } u_{x}=k x y^{d} z=\left(\left.\right|_{x} ^{\alpha}-x^{s}\right) k p x^{s}\left(1-\left.\right|_{x}\right)^{\gamma} \\
& I_{x}, x^{s}
\end{aligned}
$$

where we have used the production functions $x+x^{s}=I_{x}^{\alpha}$ and $z=I_{z}^{\gamma}=\left(1-\left.\right|_{x}\right)^{\gamma}$, the budget constraint $p_{x} x^{s}$ $=$ py $y^{d}$, and the fact that $x^{d}=l_{y}=y=y^{s}=z^{s}=z^{d}=0$ for configuration $(x / y)$. The solution to (A 2) is

$$
\begin{aligned}
& \mathrm{I}_{\mathrm{x}}=2 \alpha /(2 \alpha+\gamma), \quad \mathrm{x}^{\mathrm{s}}=\mathrm{I}_{x}^{\alpha} / 2, \quad y^{\mathrm{d}}=p_{x} \mathrm{x}^{\mathrm{s}} / \mathrm{p}_{\mathrm{y}} \\
& \mathrm{u}_{\mathrm{x}}\left(\mathrm{p}_{\mathrm{x}}, \mathrm{p}_{\mathrm{y}}\right)=\mathrm{kp}_{\mathrm{x}}(2 \alpha)^{2 \alpha} \gamma^{\gamma} / 4 p_{y}(2 \alpha+\gamma)^{2 \alpha+\gamma,}
\end{aligned}
$$

where $u_{x}\left(p_{x}, p_{y}\right)$ is the indirect utility function for a specialist of $x$.

(2.b) The corner solution for configuration $(y / x)$ is symmetric to one for $(x / y)$, given by

$$
\begin{aligned}
& l_{y}=2 \beta /(2 \beta+\gamma), \quad y^{s}=l_{y}^{\beta} / 2, \quad \quad p_{x} x^{d}=p_{y} y^{s}, \\
& u_{y}\left(p_{x}, p_{y}\right)=k p_{y}(2 \beta)^{2 \beta} \gamma^{\gamma} / 4 p_{x}(2 \beta+\gamma)^{2 \beta+\gamma},
\end{aligned}
$$

where $u_{i}\left(p_{x}, p_{y}\right)$ is the indirect utility function for a person selling good $i$.

(2.c) The utility equalization and market clearing conditions 


$$
M_{x} x^{s}\left(p_{x}, p_{y}\right)=M_{y} X^{d}\left(p_{x}, p_{y}\right) \text { and } u_{x}\left(p_{x}, p_{y}\right)=u_{y}\left(p_{x}, p_{y}\right)
$$

give corner equilibrium in market structure $P$ as

$$
\begin{aligned}
& p_{y} / p_{x}=(2 \alpha)^{\alpha}(2 \beta+\gamma)^{\beta+.5 c} /(2 \beta)^{\beta}(2 \alpha+\gamma)^{\alpha+.5 c}, \\
& \left.M_{y} / M_{x}=(2 \alpha+\gamma) /(2 \beta+\gamma)\right]^{.5 c} \\
& U_{p}=2^{\alpha+\beta-2} k \alpha^{\alpha} \beta^{\beta} \gamma^{\gamma} /(2 \alpha+\gamma)^{\alpha+.5 c}(2 \beta+\gamma)^{\beta+.5 c}
\end{aligned}
$$

where up is real income in market structure $P$. Note that the market clearing condition for $y$ is not independent of (A 5) due to $W$ alras' law. Corner equilibria in market structures $P(x z)$ and $P(y z)$ cannot be equilibrium since utility levels in the two structures are lower than in $P(x y)$ if $\alpha>\beta>\gamma$, or if the fixed learning cost $A$ is slightly smaller in producing $x$ and $y$ than in producing $z$, as shown by $Y$ ang [1990].

(3) $M$ arket structure $C$ consisting of $(x / y z),(y / x z)$, and (z/xy).

(3.a) The decision problem for configuration $(x / y z)$ is

$$
\text { Max: } u_{x}=k^{2} x y^{d} z^{d}=\left(1-x^{s}\right) k^{2}\left(p_{x} x^{s}-p_{z} z^{d}\right) z^{d} / p_{y}
$$

$$
x^{s}, z^{d}
$$

where we have used the production functions $x+x^{s}=I_{x}^{\alpha}$, the budget constraint $p_{x} x^{s}=p_{y} y^{d}+p_{z} z^{d}$, the endowment constraint $I_{x}=1$, and the fact that $x^{d}=I_{y}=y=y^{s}=I_{z}=z=z^{s}=0$ for configuration $(x / y z)$. The solution to $(A 7)$ is

$$
I_{x}=1, \quad x^{s}=2 / 3, \quad p_{y} y^{d}=p_{z} z^{d}=p_{x} x^{s} / 2, \quad u_{x}\left(p_{x}, p_{y}, p_{z}\right)=k^{2} p_{x}^{2} / 3^{3} p_{y} p_{z}
$$

(3.b) The corner solutions for configurations $(y / x z)$ and $(z / x y)$, symmetric to the one for $(x / y z)$, are given by

$$
\begin{aligned}
& l_{y}=1, \quad y^{s}=2 / 3, \quad p_{x} x^{d}=p_{z} z^{d}=p_{y} y^{s} / 2, \quad u_{y}\left(p_{x}, p_{y}, p_{z}\right)=k^{2} p_{y}^{2} / 3^{3} p_{x} p_{z} \\
& I_{z}=1, \quad z^{s}=2 / 3, \quad p_{x} x^{d}=p_{y} y^{d}=p_{z} z^{s} / 2, \quad u_{z}\left(p_{x}, p_{y}, p_{z}\right)=k^{2} p_{z}^{2} / 3^{3} p_{x} p_{y}
\end{aligned}
$$

where $u_{i}\left(p_{x}, p_{y}, p_{z}\right)$ is the indirect utility function for a person selling good $i$ in market structure $C$.

(3.c) The utility equalization and market clearing conditions

$$
u_{x}\left(p_{x}, p_{y}, p_{z}\right)=u_{y}\left(p_{x}, p_{y}, p_{z}\right)=u_{z}\left(p_{x}, p_{y}, p_{z}\right)
$$




$$
M_{x} x^{s}=M_{y} x^{d}\left(p_{x}, p_{y}, p_{z}\right)+M_{z} X^{d}\left(p_{x}, p_{y}, p_{z}\right), M_{y} y^{s}=M_{x} y^{d}\left(p_{x}, p_{y}, p_{z}\right)+M_{z} y^{d}\left(p_{x}, p_{y}, p_{z}\right)
$$

give corner equilibrium in market structure $\mathrm{C}$ as

$$
p_{x} / p_{y}=p_{z} / p_{y}=1, \quad M_{x} / M_{y}=M_{z} / M_{y}=1, \text { and } u_{c}=k^{2} / 3^{3}
$$

where $u_{c}$ is real income in market structure $C$. Note that the market clearing condition for $z$ is not independent of (A9).

All information about the three corner equilibria is summarized in the following table.

Table 2: Three Corner Equilibria

\begin{tabular}{||l|l|l|l||}
\hline $\mathrm{i}$ & Relative prices & Relative numbers & U tility ui \\
\hline $\mathrm{A}$ & & & $\alpha^{\alpha} \beta^{\beta} \gamma^{\gamma} /(a+\beta+\gamma)^{\alpha+\beta+\gamma}$ \\
\hline $\mathrm{P}$ & $\begin{array}{l}p_{y} / p_{x}=(2 \alpha)^{\alpha}(2 \beta+\gamma)^{\beta+.5 c} /(2 \beta \\
)^{\beta}(2 \alpha+\gamma)^{\alpha+.5 c}\end{array}$ & $\begin{array}{l}\mathrm{M}_{\mathrm{y}} / \mathrm{M}_{\mathrm{x}}= \\
(2 \alpha+\gamma) /(2 \beta+\gamma)]^{.5 c}\end{array}$ & $\begin{array}{l}2^{\alpha+\beta-2} \mathrm{k} \\
\alpha^{\alpha} \beta^{\beta} \gamma^{\gamma} /(2 \alpha+\gamma)^{\alpha+.5 c}(2 \beta+\gamma)^{\beta+.5 c}\end{array}$ \\
\hline $\mathrm{C}$ & $p_{x} / p_{y}=p_{z} / p_{y}=1$, & $M_{x} / M_{y}=M_{z} / M_{y}=1$ & $k^{2} / 3^{3}$ \\
\hline
\end{tabular}

\section{Appendix B: Solution of the Dynamic Programming Problem and Sequential Equilibrium}

This appendix provides technical details of the solution of the dynamic programming problem in section 3 and proof of results in Tables 2 and 3. According to the Bellman optimality principle, we use a backward decision rule to solve for the dynamic programming problem (4). Consider three nodes in period $1, A, P$, C. At node $A$, there are seven options: $A A, A P, A C, P C, P O, C P, C O$ where $A P$ is symmetric to $A C$, $P C$ symmetric to $C P, P O$ symmetric to $C O$ except that those sequences which experiment with $C$ before $P$ involve a slightly greater pricing cost. We need to consider only four of them, AA, AP, PC, and PO. Using the information about payoffs for each option in each period, given in Figure 2 and equation (4), we can compare the expected accumulated discounted real income from period 2 to period 3 for the four options. We denote the expected discounted utility accumulated after experiment pattern ij is chosen in 
period 1 by $U(i j)$ where $i, j=A, P, C, 0$; A means autarky, $P$ means the experiment with structure $P$ and the better between $A$ and $P$ being chosen, $C$ means that experiment with structure $C$ and the best among $A, P$, and $\mathrm{C}$ being chosen, and 0 means no new experiment and staying with the best among structures previously experimented with. Also the maximum value of $U$ (ij) with respect to all possible pattern ij's that is generated by option $r$ in period $t$ is denoted by $V_{t}(r)$. U sing the notations, the result of this comparison yields

$$
V_{1}(A)=\left\{\begin{array}{l}
U(P C) \text { if } s>s_{5}, \\
U(P O) \text { if } s \in\left(s_{4}, s_{5}\right) \\
U(A A) \text { if } s<s_{4}
\end{array}\right.
$$

Similarly, for node $P$ in period 1 , we can find

$$
V_{1}(P)=\left\{\begin{array}{l}
U(C O) \text { if } s>s_{1}, \\
U(00) \text { if } s<s_{1} .
\end{array}\right.
$$

where $s_{1} \equiv\left[u_{A}+(2-r) b / 3\right] /\left(u_{A}+b\right), s_{4} \equiv\left[u_{A}-(2 r b / 3)\right] /\left(u_{A}+2 b / 3\right), s_{5} \equiv\left[u_{A}+(2 b / 3)\right] /\left(u_{A}+b\right)>s_{4}$ and values of $\mathrm{U}$ (ij) are listed in Table 2. It can be shown that at node A in period 1 AP cannot be part of equilibrium. A comparison between $U(A P)$ and $U(A A)$ and between $U(P O)$ and $U(A P)$ indicates that $U(P O)>U(A P)$ iff $s>s_{6} \equiv\left[u_{A}(1-r)-2 b r / 3\right] /(1+r)\left(u_{A}+2 b / 3\right)$ and $U(A A)>U(A P)$ iff $s<s_{7}=u_{A} /\left(u_{A}+2 b / 3\right)$ where $s_{7}>s_{6}$ which implies that $U(A P)$ is either smaller than $U(A P)$ or smaller than $U(P O)$. Hence, AP will never be chosen. At node $P$ it can be shown that $O C$ cannot be equilibrium. A comparison between $U(C O)$ and $U(O C)$ and between $U(O O)$ and $U(O C)$ indicates that $U(C O)>U(O C)$ iff $s>s_{8}=\left[u_{A}+(2 / 3-r) b /(1-r)\right] /\left(u_{A}+b\right)$ and $U(00)>U(O C)$ iff $s<s_{5}$ where $s_{5}>s_{8}$ which implies that $U(O C)$ is either smaller than $U(00)$ or smaller than $\mathrm{U}(\mathrm{CO})$. Hence, OC will never be chosen at node $\mathrm{P}$ in period 1.

Node $C$ in period 1 is symmetric to node $P$ except that all experiment patterns at node $C$ involves slightly greater discounted pricing cost than those which start from node P. 
Table 3: Total Discounted Utilities for Different Experiment Patterns Starting from Period 1

\begin{tabular}{||c|l|l||}
\hline Node & $\begin{array}{l}\text { Structure } \\
\text { sequence } i j\end{array}$ & $\begin{array}{l}\text { Total discounted utility in periods } 2 \\
\text { and } 3, U(i j)\end{array}$ \\
\hline \multirow{4}{*}{$A$} & $P C$ & {$\left[s\left(u_{A}+2 b / 3\right)+s r\left(u_{A}+b\right)\right]$} \\
\cline { 2 - 3 } & $P O$ & $(s+r)\left(u_{A}+2 b / 3\right)$ \\
\cline { 2 - 3 } & AP & $u_{A}+s r\left(u_{A}+b\right)$ \\
\cline { 2 - 3 } & $A A$ & $(1+r) u_{A}$ \\
\hline \multirow{3}{*}{$P$} & CO & $(s+r)\left(u_{A}+b\right)$ \\
\cline { 2 - 3 } & $O O$ & $(1+r)\left(u_{A}+2 b / 3\right)$ \\
\cline { 2 - 3 } & $O C$ & $u_{A}+2 b / 3+s r\left(u_{A}+b\right)$ \\
\hline
\end{tabular}

where utility is discounted to period 1.

We denote the expected discounted utility accumulated after experiment pattern ijr is chosen in period 0 by $U(i j r)$ where $i, j, r=A, P, C, O$, and $A, P, C, O$ have the same meanings as for the notations for the problem in period 1. Using the information about payoffs in period 0, given in Fig. 2, equation (4), (B1), and (B2), we obtain the final solution of the dynamic programming problem as follows.

$V_{0}(A)=\left\{\begin{array}{l}s\left(u_{A}+2 b / 3\right)+V_{1}(P)=s\left(u_{A}+2 b / 3\right)+U(00)=U(P O O) \text { if } s \in\left(s_{0}, s_{1}\right) \\ u_{A}+V_{1}(A)=u_{A}+U(A A)=U(A A A) \text { if } s<s_{0} .\end{array}\right.$

where the values of $s_{i}$ are given in Table 5. 
Table 4: Total Discounted Utilities for Different Experiment Patterns Starting from Period 0

\begin{tabular}{|c|l||}
\hline $\begin{array}{l}\text { Structure } \\
\text { sequence ijr }\end{array}$ & Total discounted utility U (ijr) \\
\hline APC & $u_{A}+s r\left(u_{A}+2 b / 3\right)+s^{2}\left(u_{A}+b\right)$ \\
\hline$A P O$ & $u_{A}+(s+r) r\left(u_{A}+2 b / 3\right)$ \\
\hline$A A A$ & $\left(1+r+r^{2}\right) u_{A}$ \\
\hline$P C O$ & $s\left(u_{A}+2 b / 3\right)+r(s+r)\left(u_{A}+b\right)$ \\
\hline POO & $s\left(u_{A}+2 b / 3\right)+r(1+r)\left(u_{A}+2 b / 3\right)$ \\
\hline
\end{tabular}

where POC is excluded due to (B2).

Table 5: Values of $\mathrm{si}$

\begin{tabular}{||l|l||}
\hline \hline$i$ & \multicolumn{1}{|c|}{ Values of $s_{i}$} \\
\hline 0 & {$\left[u_{A}+2 b r(1+r) / 3\right] /\left(u_{A}+2 b / 3\right)$} \\
\hline 1 & {$\left[u_{A}+b(2-r) / 3\right] /\left(u_{A}+b\right)$} \\
\hline 2 & $\left(u_{A}-b r / 3\right) /\left(u_{A}+b / 3\right)$ \\
\hline 3 & $\left(u_{P}-b r / 3\right) /\left(u_{P}+b / 3\right)$ \\
\hline 4 & {$\left[u_{A}-(2 r b / 3)\right] /\left(u_{A}+2 b / 3\right)$} \\
\hline 5 & {$\left[u_{A}+(2 b / 3)\right] /\left(u_{A}+b\right)$} \\
\hline 6 & {$\left[u_{A}(1-r)-2 b r / 3\right] /(1+r)\left(u_{A}+2 b / 3\right)$} \\
\hline 7 & $u_{A} /\left(u_{A}+2 b / 3\right)$ \\
\hline 8 & {$\left[u_{A}+(2 / 3-r) b /(1-r)\right] /\left(u_{A}+b\right)$} \\
\hline 9 & {$\left[u_{A}-r^{2} b /(1-r)\right] /\left\{u_{A}+\left[2+r /\left(1-r^{2}\right)\right] b / 3\right\}$} \\
\hline 10 & {$\left[u_{A}-2 r b / 3(1-r)\right] /\left[u_{A}+(2 b / 3)\right]$} \\
\hline \hline
\end{tabular}

where $s_{1}>s_{0}, S_{5}>s_{4}, S_{5}>s_{8}, s_{5}>S_{9}, S_{7}>s_{6}$, and $s_{10}>s_{4}$. 
$N$ ote that $\mathrm{V}_{\mathrm{t}}(\mathrm{i})$ changes with the value ranges of $\mathrm{s}$ even if $\mathrm{t}$ and $\mathrm{i}$ are fixed. For establishing (B3), we firs show that sequences APC and APO cannot be equilibrium. To show that APC cannot be equilibrium, compare U (PCO) with U (APC) which are given in Table 4. The comparison yields

$$
U(P C O)>U(A P C) \text { iff } s>s_{9} \equiv\left[u_{A}-r^{2} b /(1-r)\right] /\left\{u_{A}+\left[2+r /\left(1-r^{2}\right)\right] b / 3\right\}
$$

A comparison between $s_{9}$ and $s_{5}$ indicates that $s_{9}<s_{5}$. This implies that $U(P C O)>U(A P C)$ if $s_{>}>s_{9}$ and $U(P O O)>U(A P C)$ if $s_{<}<s_{5}$ where $s_{9}<s_{5}$. In other words $U(A P C)$ is either smaller than $U(P C O)$ or smaller than $U(P O O)$, so that $A P C$ will never be chosen.

To show that APO cannot be equilibrium, we compare $U(A A A), U(A P O)$, and $U(P O O)$, given in Table 4. The comparison yields

$$
\begin{aligned}
& U(P O O)>U(A P O) \text { iff } s>s_{10}=\left[u_{A}-2 r b / 3(1-r)\right] /\left[u_{A}+(2 b / 3)\right] \\
& U(A P O)>U(A A A) \text { iff } s>s_{4}
\end{aligned}
$$

where $s_{4}<s_{10}$ which implies that $U(A P O)$ is either smaller than $U(P O O)$ or smaller than $U(A A A)$, so that A PO will never be chosen. (B4) and (B5) narrow down the set of candidates for the solution. Hence, we need consider only AAA, POO, and PCO. A comparison between $U(A A A), U(P O O)$, and $U(P C O)$, given in Table 4, yields the solution in Table 1.

Now let us establish the results in Figure 3. From Table 1, it is straightforward that AAAA will be chosen as a pattern of experimentation sequence if $s<50$. This implies that no structure with trade will be experimented with and updated information for any $t>0$ is the same as prior information in period 0. Individuals will not acquire information and their new decisions adjusted according to updated information is the same as one in period 0 . Hence, AAAA is the sequential equilibrium. Table 1 indicates that structure $P$ will be experimented with in period 1 if $s>s_{0}$. U pdated information in period 1 depends on values of the parameters of transactions, production, and tastes. For $k_{2}>k_{1}$, then $u_{A}>u_{p}, u_{c}$ if $k<k_{1}$; $u_{P}>u_{A}, u_{C}$ if $k \in\left(k_{1}, k_{2}\right)$; and $u_{C}>u_{P}$, $u_{A}$ if $k>k_{2}$. Suppose $k<k_{1}$. Then an individual's updated information in period 1 according to the Bayes rule is as follows. He knows values of $u_{A}$ and $u_{p}$ and that 
$u_{A}>$ up. He can use the Bayes rule to calculate that ranking uAupuc occurs with probability 1/3; ranking UAUcup occurs with probability $1 / 3$; and ranking ucuAup occurs with probability $1 / 3$. On the basis of the updated information, his dynamic programming problem from period 1 to period 3 is specified as follows.

$$
E_{1}\left(s u_{2}+r u_{3}\right)=(2 / 3)\left(s u_{A}+r u_{A}\right)+(1 / 3)(s+r)\left(u_{A}+b\right)
$$

if he tries $C$ in period 2 and chooses the optimum between $A$ and $C$.

$$
E_{1}\left(u_{2}+r u_{3}\right)=(1+r) u_{A} \text { if he does not try } C \text {. }
$$

where pricing cost 1-s is incurred in period 1 and an information gain associated with $b$ is received if he tries $\mathrm{C}$. He will try $\mathrm{C}$ iff (B4a) is greater than (B6b). A comparison between (B6a) and (B6b) yields

Structure $C$ will be experimented with in period 2 if $s>s_{2} \equiv\left(u_{A}-b r / 3\right) /\left(u_{A}+b / 3\right)$.

Since $u_{A}>u_{p}, u_{c}$ if $k<k_{1},(B 7)$, together with Table 1 , implies that the experimentation sequence is APAA but AAAA will be finally chosen if $s \in\left(\mathrm{S}_{0}, \mathrm{~S}_{2}\right)$ and the experimentation sequence is APCA but AAAA will be finally chosen if $s>s_{2}$, provided $k<k_{1}$.

Suppose $k \in\left(k_{1}, k_{2}\right)$ and $s>s_{0}$ where $k_{2}>k_{1}$. F or $s_{0}>s_{3}$, we have $s>s_{0}>s_{3}$. Following similar reasoning for establishing (B7), (B8) can be proven.

$$
\text { Structure } \mathrm{C} \text { will be experimented with in period } 2 \text { if } \mathrm{s}>\mathrm{s} 3 .
$$

Since $u_{P}>u_{A}, u_{c}$ if $k \in\left(k_{1}, k_{2}\right),(B 8)$, together with Table 1, implies that the experimentation sequence is APCP and thereby APPP will be finally chosen if $s>s_{0}>s_{3}$.

If $s_{0}<s_{3}$, then we have to consider both cases of $s \in\left(s_{0}, s_{3}\right)$ and $s_{>} s_{3}$. For $s \in\left(s_{0}, s_{3}\right), C$ will not be experimented with in period 2. Therefore, APPP is the sequential equilibrium. For $s>S_{3},(B 6)$ holds, so that the experimentation pattern is APCP and the sequence APPP will be finally chosen.

Repeating the lines of deduction, all other results in Fig. 3 can be established. 